\title{
Correlation between Hba1c, decreased HDL and Abdominal Obesity in Prediabetics of Karnataka State, South India
}

Rao $\mathrm{SN}^{1^{*}}$, Kuldeep $\mathrm{GB}^{2}$

${ }^{1}$ Professor, Department of Biochemistry, AECS Maruthi Dental College, Bangalore, Karnataka, India

${ }^{2}$ Chief Medical Administrator, Sri Krishna Sevashrama Hospital, Bangalore, Karnataka, India

Corresponding Author: Sujatha N Rao

Address: Professor, Department of Biochemistry, AECS Maruthi Dental College, Off Bannerghatta Road, Bangalore 560076, Karnataka, India; Email: sujatharao.8@gmail.com

Received date: 16 June 2020; Accepted date: 06 July 2020; Published date: 17 July 2020

Citation: Rao SN, Kuldeep GB. Correlation between Hba1c, decreased HDL and Abdominal Obesity in Prediabetics of Karnataka State, South India. Diab Res Open Access. 2020 Jul 17;2(2):38-45.

Copyright (C) 2020 Rao SN, Kuldeep GB. This is an open-access article distributed under the Creative Commons Attribution License, which permits unrestricted use, distribution, and reproduction in any medium, provided the original work is properly cited.

\begin{abstract}
This study aims to explore the possibility of the existence of dyslipidemia among prediabetics in India and to find the correlation if any, present between their glycated hemoglobin (HbA1c) levels and their lipid profile, and to identify the risk factor(s) if any, for the onset of diabetes. A cross-sectional study involving 212 individuals in Bangalore of Karnataka State, India from the period of August 2017 to February 2019 was considered for the study. Within the lipid profile, High-Density Lipoprotein (HDL) and the ratio of cholesterol to HDL displayed statistically significant differences between the means of the population of healthy nondiabetics and prediabetics. In prediabetics, HbA1c was negatively correlated with HDL. so, testing of HDL and cholesterol to HDL ratio at regular intervals for prediabetics should be made mandatory, as they fall in the risk category for developing type 2 Diabetes and this regular screening of HDL and Cholesterol to HDL ratio will prevent prediabetics from progressing into type2 diabetes later on. Regarding demographic factors, abdominal obesity was found to be statistically significantly associated with prediabetes. Hence prediabetics should follow a regular exercise regime to prevent themselves from progressing into diabetes in their later years.
\end{abstract}

\section{Keywords}

Prediabetes, HDL, Glycated Hemoglobin, Abdominal Obesity, Lipid Profile

\section{Introduction}

Diabetes Mellitus characterized by hyperglycemia constitutes a 'group of chronic, hereditary, metabolic disorders affecting millions of people worldwide each year $[1,2]$. Hyperglycemia can be determined by the glycated hemoglobin (HbA1c) value which indicates the blood glucose level over the past three months $[1,3]$.

As per WHO, individuals with HbA1c value $\leq 5.6$ are considered as non-diabetics, and individuals with HbA1c in the range $5.7-6.4$ are in the category of prediabetes and individuals with $\mathrm{HbA} 1 \mathrm{C} \geq 6.5$ are considered to be diabetics. One of the most common complications of diabetes is the presence of abnormal levels of lipids in the body, also called dyslipidemia [1]. While the pattern of dyslipidemia and its correlation with HbA1c or Fasting Blood Glucose (FBG) is studied extensively in diabetic patients [4-9], only a few studies have been attempted so far among prediabetic individuals on their lipid profile pattern and its possible correlation with FBG or HbA1c. Studies were conducted among prediabetics in North India [10,11], in Andaman and Nicobar Islands [12], among Spanish population [13], in Saudi Arabia [14], in Korea[15] and 
China[16]. Not only these study reports differed from each other, but also the fact that no studies have been conducted so far in South India to find the existence and pattern of dyslipidemia among prediabetic individuals so that early detection and timely action will reduce the economic burden on the country due to the prevention of progression of prediabetes into Type 2 Diabetes Mellitus $[17,18]$. It is a well-known fact that the HbA1c level as a predicting factor differs among races and ethnicity as the rate of glycation and RBC life span differs among racial and ethnic groups $[19,20]$. It is also proved that there is an influence of genetic factors on HbA1c levels [21].

So, not only this study is important due to the enormity of human population that has been affected with diabetes but also this study takes priority primarily due to the fact that it aims to evaluate HbA1c and its correlation with lipid profile among Indian prediabetics as India is the diabetic capital of the world [22] and the study population is chosen from Karnataka State as this state has reported $3{ }^{\text {rd }}$ highest death rate due to Diabetes in the year 2017 among all the states of India $[23,24]$. Our study aims to evaluate the lipid profile pattern and demographic data of prediabetics in Bangalore and to identify correlations between their HbA1c levels and lipid profile along with demographic data.

\section{Materials and Methods}

This is a cross-sectional study conducted at the Shree Krishna Sevashrama Hospital, Bangalore, Karnataka, India from April 2017 to January 2019. A total of 212 individuals were included in this study and matched for age and gender. After obtaining the Institutional ethical committee approval, informed consent was taken from all the individuals who participated in this study.

The subjects were divided into two groups for the study. The exclusion criteria for all the two groups comprised of pregnant and lactating women. Individuals with any medical problem or on medication were excluded from this study. Group 1 (controls) and Group 2 (prediabetics) comprised of individuals who had availed 'Master Health Checkup' plan \& 'woman wellness plan 'offered by the hospital.
The inclusion criteria constituted of individuals with HbA1c of 6.4 and below. Group 1 comprised of 'controls or Healthy Non-diabetics' with HbA1c equal to or below 5.6. Individuals with HbA1c in the range of 5.7 to 6.4 were grouped as prediabetics, formed Group 2 as per the WHO criterion. Two hundred twelve healthy individuals in the age ranging from 21 to 60 years of either sex were selected as Group 1 - controls, while 106 individuals who had HbA1c in the range of 5.7 to 6.4 were aged between 32 and 60 years and therefore considered as Group 2 - prediabetics (Fig-1).

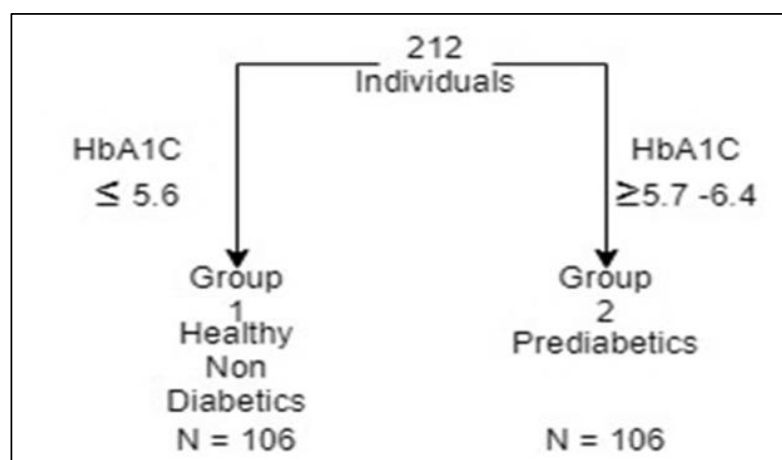

Fig-1: Flow chart for the selection of the study groups.

\section{Demographic Studies:}

The age and gender of the individuals were obtained from the hospital records. Height was measured using a wall-mounted stadiometer. Weight was measured using an electronic digital scale. BMI was calculated as weight $(\mathrm{kg})$ per height squared $\left(\mathrm{m}^{2}\right)$. BMI was segregated into standard four categories as follows: Below Normal $\left(<19 \mathrm{~kg} / \mathrm{m}^{2}\right)$ Normal $\left(19-24.9 \mathrm{~kg} / \mathrm{m}^{2}\right)$, Overweight/Above Normal $\left(25-30 \mathrm{~kg} / \mathrm{m}^{2}\right)$ and Obese $\left(>20 \mathrm{~kg} / \mathrm{m}^{2}\right)$. The waist: hip circumference was considered the measure for abdominal obesity and was categorized by its presence (yes) or its absence as (no).

\section{Sample collection and Analysis:}

Blood samples were obtained for biochemical tests. Sample collection involved $2 \mathrm{ml}$ venous fasting blood samples into labeled EDTA tubes and used for the analysis of HbA1c and $2 \mathrm{ml}$. fasting whole blood sample and was allowed to clot. Serum was separated and used for the analysis of the lipid profile (total cholesterol (TC), triglycerides (TG), high-density lipoprotein (HDL), low-density lipoprotein (LDL), very-low-density lipoprotein (VLDL), the ratio of cholesterol to HDL, the ratio of LDL to HDL). All the above analysts were analyzed by using Olympus AV 
Citation: Rao SN, Kuldeep GB. Correlation between Hba1c, decreased HDL and Abdominal Obesity in Prediabetics of Karnataka State, South India. Diab Res Open Access. 2020 Jul 17;2(2):38-45.

\section{Original Article}

auto-analyzer (using DiaSys reagents) manufactured by DiaSys Diagnostic system GmbH, Holzheim, Germany. HbA1c was estimated by the particle enhanced immune turbidimetric method. The lipid components such as total cholesterol was estimated by cholesterol oxidase-peroxidase (CHOD-POD) enzymatic photometric method, while HDL was determined by using antihuman $\beta$ lipoprotein antibodies which liberated only HDL-cholesterol which in turn was analyzed by the enzymatic (CHE, CHO, POD) method. LDL was determined by the homogeneous whole direct measurement using the color-producing enzymatic reaction as the only LDL is selectively protected and then released. TG was calculated using glycerol 3-phosphate oxidase (GPO) enzymatic method, whereas the VLDL was estimated by performing an indirect calculation from TG value using the Friedwald formula. The desirable range for TC, TG, LDL, VLDL, TC:HDL and LDL:HDL is less than $200 \mathrm{mg} / \mathrm{dl}, 150 \mathrm{mg} / \mathrm{dl}, 130 \mathrm{mg} / \mathrm{dl}, 40 \mathrm{mg} / \mathrm{dl}, 4: 1$ and 3.5:1 respectively. The desirable range of HDL was the presence of more than $40 \mathrm{mg} / \mathrm{dl}$.

Results were expressed as mean \pm S.D. A one-way ANOVA was conducted to compare the means of the populations, while Chi-square $\left(\chi^{2}\right)$ tests were conducted to evaluate the significance of the study parameters. The correlation was estimated using
Pearson's coefficient of correlation (r) between the study variables. The results of all tests with $\mathrm{p}<0.05$ were considered to be statistically significant. All the statistical analysis was performed using the SPSS statistical package version 24 .

\section{Results}

(Table-1) illustrates the descriptive statistics and the results of ANOVA for HbA1c and the lipid profiles of healthy nondiabetics and prediabetics. An increase in all the components except HDL is seen in prediabetics compared to those of healthy nondiabetics. Not only this increase was not statistically significant, but also these increased levels were still within the desirable range. Only in the case of HDL, there was a statistically significant difference between these two groups. The average levels of HDL and the ratio between TC and HDL showed only healthy nondiabetics to be in the desirable range. In prediabetic individuals, the level of HDL was significantly lower than the desirable range, and TC: HDL ratio was significantly higher than the desirable range.

Correlation (denoted as ' $r$ ') is used to measure the strength of association between two variables and ranges between -1 (perfect negative correlation) to 1 (perfect positive correlation). It is interpreted on the absolute value of the correlation, considering any value

\begin{tabular}{|c|c|c|c|}
\hline \multirow{3}{*}{ Parameter } & -1: Descriptive statisti & OVA for the stu & bles \\
\hline & \multicolumn{2}{|c|}{ Population (Mean \pm Std. Deviation) } & \multirow{2}{*}{ F value \& Significance } \\
\hline & Healthy Nondiabetics & Prediabetics & \\
\hline $\mathrm{HbA1C}$ & $5.0 \pm 0.34$ & $6.1 \pm 0.23$ & $148.8^{*}$ \\
\hline TC & $163.27 \pm 17.15$ & $168.47 \pm 20.97$ & 86.3 \\
\hline TG & $110.43 \pm 16.82$ & $119.01 \pm 42.28$ & 30.1 \\
\hline HDL & $48.41 \pm 3.11$ & $38.53 \pm 2.90$ & 120.6 * \\
\hline LDL & $103 . .61 \pm 16.80$ & $105.25 \pm 24.33$ & 32.7 \\
\hline VLDL & $22.93 \pm 3.34$ & $24 . .12 \pm 8.54$ & 29.8 \\
\hline TC: HDL & $3 \cdot 39 \pm 0.16: 1$ & $4 \cdot 3 \pm 0.49: 1$ & 154.2 * \\
\hline LDL : HDL & $2.14 \pm 0.38: 1$ & $2.69 \pm 0.72: 1$ & 23.6 \\
\hline \multicolumn{4}{|c|}{ *Statistically significant (Significance at level $\mathrm{p}<0.05$ ) } \\
\hline \multicolumn{4}{|c|}{ **Highly significant (Significance at level $\mathrm{p}<0.01$ ) } \\
\hline
\end{tabular}


Citation: Rao SN, Kuldeep GB. Correlation between Hba1c, decreased HDL and Abdominal Obesity in Prediabetics of Karnataka State, South India. Diab Res Open Access. 2020 Jul 17;2(2):38-45.

\section{Original Article}

equal to or more than 0.5 as strong, 0.3 to 0.5 as moderate, 0.1 to 0.3 as low, and less than 0.1 as a negligible relationship. (Table-2) and (Table-3) represent any correlation between the study variables identified to study the relation between HbA1c and the lipid profile within healthy non-diabetics \& prediabetics. In the case of prediabetics, there was a strong significant negative correlation of HbA1c with HDL $(r=-0.62, p<0.05)$.

Table-2: Correlation table between lipid profile and HbA1c of healthy nondiabetics

\begin{tabular}{|c|c|c|c|c|c|c|c|}
\hline Parameter & HBA1c & TC & TG & HDL & LDL & VLDL & TC:HDL \\
\hline HBA1c & 1 & & & & & & \\
\hline TC & -0.13 & 1 & & & & & \\
\hline TG & 0.26 & 0.13 & 1 & & & & \\
\hline HDL & -0.18 & $0.86^{* *}$ & 0.21 & 1 & & & \\
\hline LDL & 0.14 & $0.62^{* *}$ & $0.65^{* *}$ & 0.3 & 1 & & \\
\hline VLDL & 0.23 & 0.12 & $0.98^{* *}$ & 0.15 & $0.58^{* *}$ & 1 & \\
\hline Ch: HDL & 0.07 & $0.71^{* *}$ & 0.2 & $0.56^{* *}$ & $0.48^{* *}$ & 0.11 & 1 \\
\hline LDL: HDL & 0.22 & 0.25 & $0.79^{* *}$ & 0.15 & $0.94^{* *}$ & $0.62^{* *}$ & $0.33^{*}$ \\
\hline
\end{tabular}

Table-3: Correlation table between lipid profile and HbA1c of Prediabetics

\begin{tabular}{|c|c|c|c|c|c|c|c|}
\hline Parameter & HBA1c & TC & TG & HDL & LDL & VLDL & TC:HDL \\
\hline HBA1c & 1 & & & & & & \\
\hline TC & -0.36 & 1 & & & & & \\
\hline TG & 0.11 & -0.38 & 1 & & & & \\
\hline HDL & $-0.62{ }^{*}$ & 0.33 & -0.5 & 1 & & & \\
\hline LDL & -0.4 & 0.29 & -0.57 & 0.35 & 1 & & \\
\hline VLDL & -0.1 & -0.37 & $0.83^{* *}$ & -0.56 & 0.08 & 1 & \\
\hline TC: HDL & 0.24 & $0.79^{* *}$ & -0.09 & -0.35 & -0.04 & -0.21 & 1 \\
\hline LDL: HDL & -0.15 & 0.21 & 0.11 & 0.15 & $0.96^{* *}$ & 0.16 & 0.05 \\
\hline \multicolumn{8}{|c|}{${ }^{*} \mathrm{p}<0.05,{ }^{* *} \mathrm{p}<0.01$} \\
\hline
\end{tabular}

(Table-4) displays the data of demographic studies of healthy nondiabetics and prediabetics. Age showed a statistically significant association with prediabetes. (Pearson's Chi-square $\left.\left(\mathrm{x}^{2}\right)=52.48, \mathrm{p}<0.01\right)$. The majority of prediabetic individuals $(58 \%)$ were from the age group 46-6oyears while the majority of healthy non diabetics (51\%) were from the age group 32-45 years in this study. Similarly, the association between gender and prediabetes was statistically significant, $\mathrm{x}^{2}=22.52, \mathrm{p}<0.05$. Males were more susceptible to prediabetes (66\%) than females (34\%). Regarding BMI, the association between BMI and prediabetes was statistically not significant. $\mathrm{X}^{2}=6.33, \mathrm{p}>0.05$. None of the individuals were in the 'Below Normal' category. In fact, the majority of the prediabetic individuals were in the 'Normal' category (96\%). Only $4 \%$ of Prediabetics and $1 \%$ of healthy nondiabetics were in the 'Above Normal' category. Abdominal obesity showed a significant association with prediabetes, $\mathrm{x}^{2}=29.82, \mathrm{p}<$ o.01. Among prediabetic individuals, $20 \%$ of them had abdominal obesity while only $1 \%$ of healthy nondiabetic individuals had abdominal obesity.

\section{Discussion}

Assessment of lipid profile and demographic data in 
Citation: Rao SN, Kuldeep GB. Correlation between Hba1c, decreased HDL and Abdominal Obesity in Prediabetics of Karnataka State, South India. Diab Res Open Access. 2020 Jul 17;2(2):38-45.

\begin{tabular}{|c|c|c|c|c|c|}
\hline \multicolumn{6}{|c|}{ Table-4: Demographic data of healthy non diabetics and prediabetic individuals } \\
\hline Variables & Group & Healthy Nondiabetics & Prediabetics & $X^{2}$ & P Value \\
\hline \multirow{3}{*}{ Age Group } & $21-31$ & $19(18 \%)$ & $\mathrm{o}(\mathrm{o} \%)$ & \multirow{3}{*}{$52.48^{* *}$} & \multirow{3}{*}{ o } \\
\hline & $32-45$ & $54(51 \%)$ & $45(42 \%)$ & & \\
\hline & $46-60$ & $33(31 \%)$ & $61(58 \%)$ & & \\
\hline \multirow{2}{*}{ Gender } & Males & $52(49 \%)$ & $70(66 \%)$ & \multirow{2}{*}{$22.52^{*}$} & \multirow{2}{*}{0.0182} \\
\hline & Females & $54(51 \%)$ & $36(34 \%)$ & & \\
\hline \multirow{5}{*}{ BMI } & Below & \multirow{2}{*}{ o $(0 \%)$} & \multirow{2}{*}{ o $(0 \%)$} & \multirow{5}{*}{6.33} & \multirow{5}{*}{0.056} \\
\hline & Normal & & & & \\
\hline & Normal & $105(99 \%)$ & $101(95 \%)$ & & \\
\hline & Above Normal & $1(1 \%)$ & $5(5 \%)$ & & \\
\hline & Obese & o $(0 \%)$ & o $(0 \%)$ & & \\
\hline \multirow{2}{*}{$\begin{array}{l}\text { Abdominal } \\
\text { Obesity }\end{array}$} & Yes & $1(1 \%)$ & $21(20 \%)$ & \multirow{2}{*}{$29.82^{*}$} & \multirow{2}{*}{ o } \\
\hline & No & $105(99 \%)$ & $85(80 \%)$ & & \\
\hline \multicolumn{6}{|c|}{ *Statistically significant (Significance at level $\mathrm{p}<0.05$ ) } \\
\hline \multicolumn{6}{|c|}{ **Highly significant (Significance at level p<0.01) } \\
\hline
\end{tabular}

our cross-sectional study of South Indian prediabetics had noted statistically significant changes only in the HDL component of lipid profile and the significant presence of abdominal obesity. BMI did not show any significant association with prediabetes. This finding was not seen in the study of young Saudi prediabetics which assessed their lipid profile, total antioxidant status (TAS), demographic, and lifestyle data [14]. They had observed statistically significant changes in all the components of the lipid profile and the presence of significantly increased BMI in their study. There was a positive correlation between HbA1c and TC, TG, LDL$\mathrm{C}$, BMI, and central obesity while a negative correlation was reported between $\mathrm{HbA1c}$ and HDL Cholesterol and TAS [14]. Analysis of the data obtained by Korea National Health and Nutrition examination survey from the study of their prediabetics had shown significantly higher levels of Total TC, TG, LDL, TC to HDL-C ratio, TG to HDL-C ratio, LDL-C to HDL-C ratio, and significantly increased urinary albumin excretion in prediabetic women [15].

But in Our Study, only HDL component was significantly altered and decreased. Albuminuria was not present and there was no statistically significant increase in BMI. In a study that investigated the relationship between Insulin Resistance (IR) and dyslipidemia along with BMI, WHR, Fasting C peptide in prediabetics and type 2 diabetes mellitus patients in China, found that the BMI, WHR and the TG component of the lipid profile were significantly altered and increased in prediabetic individuals [16]. But in our study, BMI was not significantly altered among prediabetics. Though the findings similar to that of our study report was observed in an investigation among Spanish prediabetics, it had also reported hypertension and a significant increase in TG [13] which was not noted in our study. Although lowered HDL and increased TG had shown a strong association with abdominal obesity in women and with general obesity in men, it was based on the waist to height ratio (WHtR) criterion [13], whereas in our study it was based on waist to hip circumference ratio. Another study evaluating cardiovascular risk assessments in prediabetes and diabetes, fasting lipid profile showed a significant increase only in the TC among prediabetics [11] which is not in accordance with our report. None of the lipid components showed significant changes among diabetic individuals in their study [11] which was not the objective of our study.

In a study of myocardial performance index in prediabetes and its correlation with other cardiovascular risk factors, assessment of lipid profile, 
BMI, WHR was carried out, it was noted that BMI, WHR, TC, TG, LDL, VLDL were all significantly higher and HDL was significantly lower in prediabetic subjects [10]. Similarly, a retrospective study that tracked lipid profile and atherogenic indices among prediabetics of Andaman Nicobar Islands, noted that all the lipid profile components except HDL were significantly increased and HDL was significantly decreased in prediabetics [12]. These reports were not in accordance with our report.

One limitation of our study is its cross-sectional nature. The study population was from only one hospital in Bangalore. But this hospital caters to a random study population, which represented the true population of Karnataka State of South India.

\section{Conclusion}

In our study of the lipid profile in prediabetics, of Karnataka State, India, a negative correlation of HDL with HbA1c was observed. So, prediabetics can prevent themselves from developing diabetes in their later years by testing their HDL and Cholesterol to HDL ratio at regular intervals as they fall in the risk category for progressing into Typez diabetes. So, periodic monitoring of HDL levels and Cholesterol to HDL ratio should be made mandatory for prediabetics. Regarding demographic factors, abdominal obesity and not the BMI is the risk factor for prediabetes. The age group between 32 to 60 is vulnerable to the onset of prediabetes. So, prediabetics should implement a regular exercise regime to prevent themselves from becoming diabetics in their later years.

\section{Acknowledgements}

The authors thank Sri Krishna Sevashrama Hospital, Bangalore for giving us an opportunity to conduct this study. Special thanks to the Nursing Superintendent Mrs. Judith Fernandes for her help in recording the individual's age, gender, height and weight, waist, and hip circumference.

\section{Conflict of Interest}

All authors have read and approved the final version of the manuscript. The authors have no conflicts of interest to declare.

\section{Funding Organizations}

This research received no specific grant from any funding agency in the public, commercial, or nonprofit sectors.

\section{References}

[1] Alam R, Verma MK, Verma P. Glycated hemoglobin as a dual biomarker in type 2 diabetes mellitus predicting glycemic control and dyslipidemia risk. Int. J. Life. Sci. Scienti. Res. 2015 Oct;1(2):62-65.

[2] Babikr WG, Alshahrani AS, Hamid HG, Abdelraheem AH, Shalayel MH. The correlation of HbA1c with body mass index and HDL-cholesterol in type 2 diabetic patients. Biomed Res. 2016;27(4):128083.

[3] Vinod MR, Gyawali P, Raut PP, Regmi P, Psd K, Singh DR, Gyawali P. Association between glycaemic control and serum lipid profile in type 2 diabetic patients: Glycated haemoglobin as a dual biomarker. Biomed Res. 2011;22(3):375-80.

[4] Sarbini D, Huriyati E, Sadewa AH, Wahyuningsih MSH. Correlation Between Lipid Profiles with Pancreatic $\beta$ - Cell Function in Patients with Type 2 Diabetes Mellitus. 4th International Symposium on Health Research (ISHR 2019). Advances in Health Sciences Research. 2020;22:298-304.

[5] Shafique S, Daud Mirza SS, Tabassum S, Faraz N. Frequency of Dyslipidemia In Type 2 Diabetic Patients In Karachi. JBUMDC. 2019;9(2):133-36.

[6] Shah SH, Hameed T, abbas Bokhari F, Khan Z, Ahmed BH, Yousaf M, Shah AS, Lodhi WS, Ishtiaq H, ul Hassan N, ur Rehman A. 31. Configuration of dyslipidemia in patients with type 2 diabetes mellitus visiting tertiary care hospital Quetta-Pakistan. Pure Appl Bio. 2019 Feb 28;8(1):288-94.

[7] Arab GA, Zahedi M, Kazemi Nejad V, Sanagoo A, Azimi M. Correlation between hemoglobin a1c and serum lipid profile in type 2 diabetic patients referred to the diabetes clinic in gorgan, iran. J Clin Basic Res. 2018 Apr 10;2(1):26-31.

[8] Hussain A, Ali I, Ijaz M, Rahim A. Correlation between hemoglobin A1c and serum lipid profile in Afghani patients with type 2 diabetes: hemoglobin A1c prognosticates dyslipidemia. Ther Adv Endocrinol Metab. 2017 Apr;8(4):51-57. [PMID: 28507727]

[9] Devkar V, Desai P, Prajapati P, Rao S, Desai A. Correlation between glycated hemoglobin and 
dyslipidemia in patients with type 2 diabetes mellitus in a tertiary care hospital, Maharashtra, India. Int J Sci Study. 2016 Sep 1;4(6):121-24.

[10] Kamble TK, Kapse A, Kumar S, Acharya S, Ghule A. Study of Myocardial Performance Index in Prediabetes and Its Correlation with Other Cardiovascular Risk Factors. Journal of Evolution of Medical and Dental Sciences. 2020 Mar 9;9(10):721-6.

[11] Chakraborty M, Singh P, Dsouza JMP, Pethusamy K, Thatkar PV. Fasting and postprandial lipid parameters: A comparative evaluation of cardiovascular risk assessment in prediabetes and diabetes. J Family Med Prim Care. 2020 Jan 28;9(1):287-92. [PMID: 321106o6]

[12] Chakraborty M, Gouroju S, Singh P, Thatkar PV, Bagchi D. Tracking lipid profile and atherogenic indices in the prediabetics of Andaman Nicobar Islands: A retrospective hospital-based study. J Family Med Prim Care. 2019 Mar;8(3):1117-22. [PMID: 3104126o]

[13] Sangrós FJ, Torrecilla J, Giráldez-García C, Carrillo L, Mancera J, Mur T, Franch J, Díez J, Goday A, Serrano R, García-Soidán FJ, Cuatrecasas G, Igual D, Moreno A, Millaruelo JM, Carramiñana F, Ruiz MA, Pérez FC, Iriarte Y, Lorenzo Á, González M, Álvarez B, Barutell L, Mayayo MS, Del Castillo M, Navarro E, Malo F, Cambra A, López R, Gutiérrez MÁ, Gutiérrez L, Boente C, Mediavilla JJ, Prieto L, Mendo L, Mansilla MJ, Ortega FJ, Borras A, Sánchez LG, Obaya JC, Alonso M, García F, Gutiérrez ÁT, Hernández AM, Suárez D, Álvarez JC, Sáenz I, Martínez FJ, Casorrán A, Ripoll J, Salanova A, Marín MT, Gutiérrez F, Innerárity J, Álvarez MDM, Artola S, Bedoya MJ, Poveda S, Álvarez F, Brito MJ, Iglesias R, Paniagua F, Nogales P, Gómez Á, Rubio JF, Durán MC, Sagredo J, Gijón MT, Rollán MÁ, Pérez PP, Gamarra J, Carbonell F, García-Giralda L, Antón JJ, de la Flor M, Martínez R, Pardo JL, Ruiz A, Plana R, Macía R, Villaró M, Babace C, Torres JL, Blanco C, Jurado Á, Martín JL, Navarro J, Sanz G, Colas R, Cordero B, de Castro C, Ibáñez M, Monzón A, Porta N, Gómez MDC, Llanes R, Rodríguez JJ, Granero E, Sánchez M, Martínez J, Ezkurra P, Ávila L, de la Sen C, Rodríguez A, Buil P, Gabriel P, Roura P, Tarragó E, Mundet X, Bosch R, González JC, Bobé MI, Mata M, Ruiz I, López F, Birules M, Armengol O, de Miguel RM, Romera L, Benito B, Piulats N, Bilbeny B, Cabré JJ, Cos X, Pujol R, Seguí M, Losada C, de Santiago AM, Muñoz P, Regidor
E. Association of General and Abdominal Obesity With Hypertension, Dyslipidemia and Prediabetes in the PREDAPS Study. Rev Esp Cardiol (Engl Ed). 2018 Mar;71(3):170-77. [PMID: 28789915]

[14] Mohieldein AH, Hasan M, Al-Harbi KK, Alodailah SS, Azahrani RM, Al-Mushawwah SA. Dyslipidemia and reduced total antioxidant status in young adult Saudis with prediabetes. Diabetes \& Metabolic Syndrome: Clinical Research \& Reviews. 2015 Oct 1;9(4):287-91.

[15] Nam GE, Han K, Kim DH, Park YG, Yoon YJ, Kim YE, Lee S, Lee S, Roh YK. Relationship between dyslipidemia and albuminuria in prediabetic adults: the Korea National Health and Nutrition Examination Survey 2011-2012. Endocrine. 2015 Mar;48(2):557-65. [PMID: 25205446]

[16] Qiu-yun LI, Cai-ning W, Li-ping S. Relationship between Insulin Resistance and Dyslipidemia in Patients with Prediabetes and Type 2 Diabetes Mellitus. Chinese General Practice. 2011;14(24):2716-19.

[17] Senthilkumar N, Anandhasayanam A., Senthilvelu A., Rasheed M. Correlation observation Between HbA1c Values and Lipid Profile in Type II Diabetes Mellitus out patients. International Journal of Pharma Research \& Review. 2016;5(5):9-20.

[18] Maharjan P, Pandeya D, Joshi G, Hona S, Bhatta B, Hamza A. AlDahr MS. Glycated hemoglobin (Hba1c) is a predictor of dyslipidemia in type 2 diabetes Nepalese patients. Int J Adv Res. 2017;5(2):113-21.

[19] Cohen RM, Smith EP, Arbabi S, Quinn CT, Franco RS. Do red blood cell indices explain racial differences in the relationship between hemoglobin A1c and blood glucose?. The Journal of pediatrics. 2016 Sep 1;176:7-9. [20] Wang A, Shi Q, He JC, Uribarri J. Comparison of Sensitivity of HbA1c with Fasting Blood Glucose for Diagnosing Prediabetes in Chinese Americans. Current Research in Diabetes \& Obesity Journal. 2017;5(1):1-6.

[21] Snieder H, Sawtell PA, Ross L, Walker J, Spector $\mathrm{TD}$, Leslie $\mathrm{RD}$. $\mathrm{HbA}(1 \mathrm{c})$ levels are genetically determined even in type 1 diabetes: evidence from healthy and diabetic twins. Diabetes. 2001 Dec;50(12):2858-63. [PMID: 11723071]

[22] Patel V, Shastri M, Gaur N, Jinwala PR, Kadam AY. A study in prevalence of diabetic nephropathy in recently detected cases of type 2 diabetes mellitus as evidenced by altered creatinine clearance, urinary albumin and serum creatinine, with special emphasis 
Citation: Rao SN, Kuldeep GB. Correlation between Hba1c, decreased HDL and Abdominal Obesity in Prediabetics of Karnataka State, South India. Diab Res Open Access. 2020 Jul 17;2(2):38-45.

\section{Original Article}

on hypertension, hypercholesterolemia and obesity. Int J Adv Med. 2018 Mar 21;5(2):351-55.

[23] Anjana RM, Deepa M, Pradeepa R, Mahanta J, Narain K, Das HK, Adhikari P, Rao PV, Saboo B, Kumar A, Bhansali A, John M, Luaia R, Reang T, Ningombam S, Jampa L, Budnah RO, Elangovan N, Subashini R, Venkatesan U, Unnikrishnan R, Das AK, Madhu SV, Ali MK, Pandey A, Dhaliwal RS, Kaur T, Swaminathan S, Mohan V; ICMR-INDIAB Collaborative Study Group. Prevalence of diabetes and prediabetes in 15 states of
India: results from the ICMR-INDIAB population-based cross-sectional study. Lancet Diabetes Endocrinol. 2017 Aug;5(8):585-96. [PMID: 28601585]

[24] Tandon N, Anjana RM, Mohan V, Kaur T, Afshin A, Ong K, Mukhopadhyay S, Thomas N, Bhatia E, Krishnan A, Mathur P. The increasing burden of diabetes and variations among the states of India: the Global Burden of Disease Study 1990-2016. The Lancet Global Health. 2018 Dec 1;6(12):e1352-62. 